\title{
Primary Sarcoma of the Head and Neck: Three Years' Experience in a Tertiary Care Cancer Center
}

\author{
Sanjiban Patra ${ }^{1}$ Priti Trivedi ${ }^{1}$ Anand Shah ${ }^{2}$ \\ ${ }^{1}$ Department of Oncopathology, The Gujarat Cancer and Research \\ Institute, Ahmedabad, Gujarat, India \\ 2Department of Community Oncology, The Gujarat Cancer and \\ Research Institute, Ahmedabad, Gujarat, India
}

\begin{abstract}
Address for correspondence Priti Trivedi, MD, Department of Oncopathology, The Gujarat Cancer and Research Institute, New Civil Hospital Campus, Asarwa, Ahmedabad 380016, Gujarat, India (e-mail: priti_patho@yahoo.co.in).
\end{abstract}

Asian J Oncol 2021;8:8-14.

\begin{abstract}
Keywords

- head and neck sarcoma

- immunohistochemistry

- recurrence

Introduction Sarcomas are a heterogeneous group of malignancies originating from the transformed cells of mesenchymal lineage, representing only $1 \%$ of all the primary tumors arising within the head and neck region with a prevalence range of 4 to $10 \%$. They are biologically different from the sarcomas of other sites because of the smaller size of the tumor at the time of presentation and higher chances of local recurrences. Due to the rarity in adults, there are very few studies on sarcomas of the head and neck. The aim of this study was to analyze the frequency and spectrum of primary sarcomas in the head and neck region.

Materials and Methods This is a retrospective descriptive study. The authors analyzed 40 cases of histologically and immunohistochemically proven primary sarcomas arising in the head and neck region according to three age groups, pediatric ( $<12$ years), adolescent (12-19 years), and adults ( $>19$ years).

Results Primary sarcomas represented $0.06 \%$ and $2.4 \%$ of total cancer cases and total sarcoma cases, respectively. Embryonal rhabdomyosarcoma was the most common histologic type, and nasopharynx the most common location in the pediatric population. Osteoblastic osteosarcomas and Ewing's sarcoma were typical variants in adolescent age, affecting the hemimandible predominantly. In adults, osteosarcomas were commonest followed by conventional grade 1 chondrosarcoma. Treatment was planned according to the stage and grade of the tumor. Out of the 40 patients, 19 (47.5\%) had a disease relapse within a period of 6 months from the completion of therapy.

Conclusion Head and neck sarcomas are notorious to recur. A timely and accurate diagnosis, proper staging, and multidisciplinary treatment plan can yield good patient outcomes.
\end{abstract}

\section{Introduction}

Primary head and neck sarcomas are rare, representing only $1 \%$ of all primary tumors arising in the head and neck region $^{1}$ and 4 to $10 \%$ of all sarcomas in the body. ${ }^{2}$ Sarcomas

published online May 06, 2021
DOI https://doi.org/

$10.1055 / \mathrm{s}-0041-1728219$

ISSN 2454-6798 are of two types: soft tissue sarcomas and bone/cartilage sarcomas $^{3}$ originating from mesenchymal cells including bone, cartilage, muscle, fat, blood vessels, and nerves. Sarcomas of the head and neck have a wide spectrum of histological subtypes and sites of origin but are kept together because

(C) 2021. Spring Hope Cancer Foundation \& Young Oncologist Group of Asia.

This is an open access article published by Thieme under the terms of the Creative Commons Attribution-NonDerivative-NonCommercial-License, permitting copying and reproduction so long as the original work is given appropriate credit. Contents may not be used for commercial purposes, or adapted, remixed, transformed or built upon. (https://creativecommons.org/licenses/by-nc-nd/4.0/).

Thieme Medical and Scientific Publishers Pvt. Ltd. A-12, 2nd Floor, Sector 2, Noida-201301 UP, India 
of similarities in prognostic factors, clinical presentation, an origin from the embryonic mesoderm, and overall outcome. ${ }^{4}$ Management of these neoplasms poses a great challenge to the clinicians. ${ }^{5}$ The main modality of treatment is complete resection. ${ }^{6}$ Due to rarity in adults, there are few studies on sarcomas of head and neck. The present study was aimed to analyze the occurrence, pattern, and spectrum of primary sarcomas in the head and neck region.

\section{Materials and Methods}

A retrospective study was conducted in the department of pathology, at a tertiary care cancer center in western India to analyze the incidence and pattern of primary sarcomas arising in the head and neck region in different age groups within the period of 3 years (January 2017 to December 2019), based on the analysis of 40 patients with histologically proven sarcoma of head and neck. The total number of cancer patients and sarcoma patients registered in this period (2017-2019) were recorded from the medical record department. The patient population was divided into three subgroups according to the age at first presentation and registration at the center: pediatric ( $<12$ years), adolescence ( $12-19$ years), and adults ( $>19$ years). Detailed clinical history, radiological data, histopathological diagnosis, immunohistochemistry findings, and data on tumor recurrence and tumor metastasis were obtained from patients' data records. Descriptive statistics had been used.

Immunohistochemistry was done in all cases to confirm the diagnosis at first presentation in fully automated machine (Ventana XT Benchmark) using monoclonal antibody to AE1 (anion exchanger1/3) (Cell Marque-1:100, AE1/AE3), epithelial membrane antigen (EMA) (Cell Marque-1:100, E29), CD99 (Thermo Scientific-1:50, H036-1.1), vimentin (BioGene-1:200, B9), desmin (BioGenex-1:50, D33), MyoD1 (ThermoScientific-1:50, clone 5.8A), CD34(Dako-1:50, clone QBEnd10), CD31 (Dako-1:50, clone JC70A), Friend leukemia integration-1 (FLI1) (Cell Marque-1:75, MRQ-1), transducin-like enhancer of split (TLE 1) (Thermo Scientific-1:100, OT1H2), factor VIII-related antigen (Thermo Scientific-1:50, clone F8/86), S100 (Thermo Scientific-1:100, clone 4C4.9), SRY-related HMG-box 10 (SOX 10) (Ventana-RTU, clone SP267), smooth muscle actin (SMA) (Thermo Scientific-1:50, clone 1A4), CD45 (Thermo Scientific-1:100, RA/RO), neuron-specific enolase (NSE) (Leica-1:30, NCL-NSE-435), special AT-rich sequence-binding protein 2 (SATB2) (cell signaling-1:100, E8R8H), CD68 (Cell Marque-1:100, PG-M1), and Bcl2 (Cell Marque-1:100, clone 124).

\section{Results}

The total number of sarcoma cases were 1,663 out of total registered 65,129 cancer cases in our institute from 2017 to 2019. Among those, the number of primary sarcoma cases of head and neck was 40 , registered within the said time period, with an age range from 3 to 75 years. They were divided into three subgroups. Results were analyzed according to the three age groups. Primary sarcoma represented $0.06 \%$ of total cancers and $2.4 \%$ of total sarcoma cases in our study.

\section{Pediatric Population ( $<12$ Years; $\boldsymbol{n}=\mathbf{5}$ )}

The mean age was 4.2 years (range 3-6 years) with a male: female ratio of $4: 1$. The most common tumor location was nasopharynx. The most common diagnosis was embryonal rhabdomyosarcoma (ERMS) (4/5) ( case of chondroblastic variant of osteosarcoma (OS) affecting the occipital bone (-Table 1). Three of the ERMS cases were staged as TNM stage II, intermediate-risk, and the remaining one was staged as TNM stage I, low-risk group. All of them received adjuvant chemotherapy (CT) as well as intensity-modulated radiation therapy (IMRT). Two of them had tumor recurrence within 6 months, and in one patient the tumor size was almost unchanged despite IMRT. One patient of chondroblastic OS who had undergone surgery and received adjuvant $\mathrm{CT}$ as well as RT also developed local tumor recurrence after 3 months of completion of therapy (-Table 1).

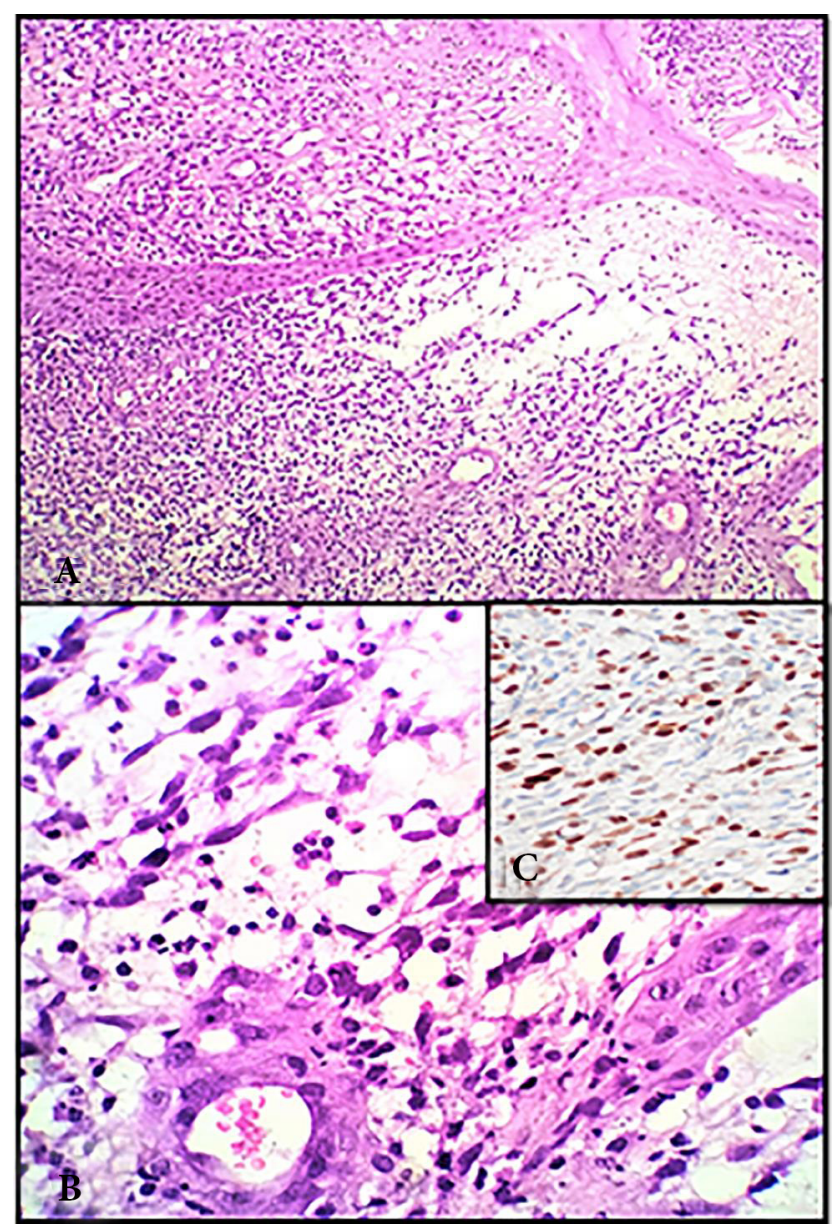

Fig. 1 Embryonal rhabdomyosarcoma. (A) Subepithelial infiltration by discrete round-to-spindle cells in partly myxoid stroma ( $\mathrm{H} \& \mathrm{E} \times 10)$; (B) these cells having oval to spindle hyperchromatic nuclei and scanty tapered cytoplasm (H\&E $\times 40)$; and $(C)$ the tumor cells express nuclear MyoD1 (immunohistochemistry $[\mathrm{IHC}] \times 40$ ). 
Table 1 Demography and clinicopathological parameters of sarcomas in pediatric age group

\begin{tabular}{|l|l|l|l|l|l|l|l|}
\hline S. No. & Age $(\mathrm{y}) /$ sex & Site of tumor & $\begin{array}{l}\text { Histopathology } \\
\text { diagnosis }\end{array}$ & $\begin{array}{l}\text { Positive IHC } \\
\text { markers }\end{array}$ & $\begin{array}{l}\text { TNM stage/risk } \\
\text { group/grade }\end{array}$ & Therapy & Recurrence \\
\hline 1 & $3 / \mathrm{M}$ & $\begin{array}{l}\text { Nasopharynx, left } \\
\text { nasal cavity }\end{array}$ & ERMS & $\begin{array}{l}\text { Vimentin, } \\
\text { desmin, MyoD1 }\end{array}$ & II, intermediate risk & CT + IMRT & Yes \\
\hline 2 & $3 / \mathrm{M}$ & $\begin{array}{l}\text { Nasopharynx and } \\
\text { columella of nose }\end{array}$ & ERMS & $\begin{array}{l}\text { Vimentin, } \\
\text { desmin, MyoD1 }\end{array}$ & II, intermediate risk & CT + IMRT & Yes \\
\hline 3 & $4 / \mathrm{F}$ & Nasopharynx & ERMS & $\begin{array}{l}\text { Vimentin, } \\
\text { desmin, MyoD1 }\end{array}$ & II, intermediate risk & CT + IMRT & No \\
\hline 4 & $5 / \mathrm{M}$ & Occipital bone & $\begin{array}{l}\text { Chondroblastic } \\
\text { OS }\end{array}$ & $\begin{array}{l}\text { S100 (chondroid } \\
\text { part), vimentin }\end{array}$ & IIA, high grade & S + CT + RT & Yes \\
\hline 5 & $6 / \mathrm{M}$ & $\begin{array}{l}\text { Conal and extra- } \\
\text { conal component } \\
\text { of right orbit }\end{array}$ & ERMS & Iesmin, MyoD1 & I, low risk & IMRT & No \\
\hline
\end{tabular}

Abbreviations: CT, chemotherapy; ERMS, embryonal rhabdomyosarcoma; F, female; IMRT, intensity-modulated radiation therapy; M, male; OS, osteosarcoma; RT, radiotherapy; $\mathrm{Y}$, year.

\section{Adolescent Population (12-19 Years; $\boldsymbol{n}=7$ )}

The mean age was 15.8 years (range $12-18$ years) with slight female preponderance (male:female $=1: 1.3$ ). Out of seven cases, three and four patients had soft tissue and bone sarcoma, respectively. Common diagnoses in this age group were Ewing's sarcoma/peripheral neuroectodermal tumor (ES/PNET) (2/7) and OS (2/7) including small-cell type ( $\mathbf{- F i g . 2 A}$ ) followed by alveolar rhabdomyosarcoma (ARMS; - Fig. 2B), fibrosarcoma, and malignant peripheral nerve sheath tumor (MPNST), one case each. Hemimandible was the commonest location affected by the tumor. Radiologically, osteosarcomas presented with lytic and sclerotic lesions in the bone with a cortical breach, periosteal reaction, and new bone formation along with associated soft tissue component. Almost all the sarcomatous lesions were hypointense in T1-weighted (T1W) and hyperintense on T1-weighted (T2W) images. Immunohistochemistry (IHC), stage, grade, and treatment of the tumors have been summarized in - Table 2.

Treatment volume was designed to cover the primary site plus a tumor-free margin. Two out of three patients having soft tissue sarcoma underwent surgical excision. One of them received only adjuvant RT (6,600 cGy). The other patient, after completion of postoperative radiation therapy (6,600 cGy), received systemic chemotherapy with an ifosfamide-based regimen considering the high-grade and incomplete surgical clearance of the tumor. One patient having ARMS was treated with standard vincristine, doxorubicin and, cyclophosphamide (VDC) chemotherapy. Two patients having ES/PNET received neoadjuvant chemotherapy with VDC alternating with ifosfamide and etoposide (IE). After completion of chemotherapy, local disease control was done by surgery only in a younger (12-year-old) patient and by surgery, along with RT (5,000 cGy) in another who had microscopic residual disease after surgical resection. Two patients who had OS including the small-cell type received neoadjuvant chemotherapy with cisplatin, doxorubicin, and high-dose methotrexate followed by surgical resection.

Three out of seven patients had tumor recurrence within 6 months of completion of therapy ( - Table 2 ).

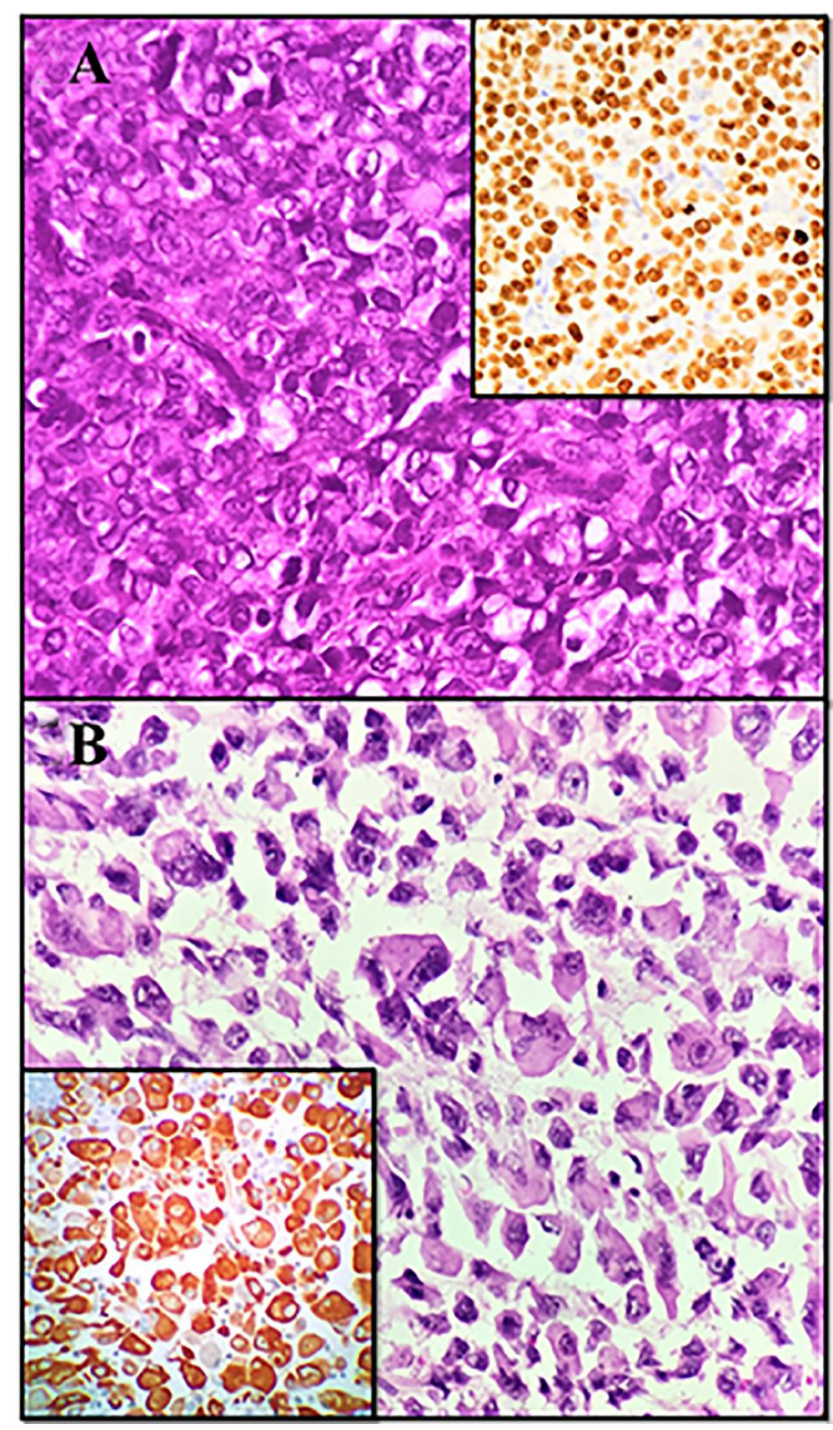

Fig. 2 (A) Small-cell osteosarcoma: tumor cells have round hyperchromatic nuclei, small nucleoli, and scanty cytoplasm (H\&E, ×40) (inset: strong nuclear special AT-rich sequence-binding protein 2 (SATB2) expression in tumor cells, immunohistochemistry [IHC] $\times 40$ ). (B) Alveolar rhabdomyosarcoma (ARMS): rhabdoid tumor cells with pleomorphic round-to-oval hyperchromatic nuclei, prominent nucleoli, and abundant eosinophilic cytoplasm (H\&E, $\times 40$ ); (inset: strong cytoplasmic desmin reactivity by these cells $(\mathrm{IHC} \times 40)$. 
Table 2 Demography and clinicopathological parameters of sarcomas in adolescent patients

\begin{tabular}{|c|c|c|c|c|c|c|c|}
\hline S. No. & $\begin{array}{l}\text { Age } \\
\text { (y)/sex }\end{array}$ & Site & $\begin{array}{l}\text { Histopathology } \\
\text { diagnosis }\end{array}$ & Positive IHC markers & Stage/grade & Therapy & Recurrence \\
\hline 1 & $12 / \mathrm{F}$ & Hemimandible (L) & ES/PNET & Vimentin, CD99, FLI1, NSE & IA, grade 3 & $C T+S$ & No \\
\hline 2 & $13 / \mathrm{F}$ & C7 vertebral body & Small-cell OS & Vimentin, SATB2 & IIA, high grade & $\mathrm{CT}+\mathrm{S}$ & Yes \\
\hline 3 & $15 / M$ & Hemimandible (R) & Osteoblastic OS & Vimentin, SATB2 & IIA, high grade & $\mathrm{CT}+\mathrm{S}$ & No \\
\hline 4 & $17 / \mathrm{M}$ & Nasal cavity (L) & ARMS & Vimentin, desmin, MyoD1 & II, intermediate risk & $\mathrm{CT}$ & No \\
\hline 5 & $18 / \mathrm{M}$ & $\begin{array}{l}\text { Frontal bone and } \\
\text { surrounding soft } \\
\text { tissue }\end{array}$ & ES/PNET & Vimentin, CD99, FLI1 & $1 \mathrm{~A}$ grade 3 & $\mathrm{~S}+\mathrm{RT}+\mathrm{CT}$ & Yes \\
\hline 6 & $18 / \mathrm{F}$ & Hemimandible (R) & Fibrosarcoma & Vimentin & $\begin{array}{l}\text { FNCLCC grade } 1 \\
\text { P } 2 \text { N0 M0 }\end{array}$ & $\mathrm{S}+\mathrm{RT}$ & No \\
\hline 7 & $18 / \mathrm{F}$ & $\begin{array}{l}\text { Retromolar } \\
\text { trigone }(R)\end{array}$ & MPNST & S100 (f), SOX10, vimentin & $\begin{array}{l}\text { FNCLCC grade } 3 \\
\text { pT3 N0 M0 }\end{array}$ & $\mathrm{S}+\mathrm{RT}+\mathrm{CT}$ & Yes \\
\hline
\end{tabular}

Abbreviations: AE1/AE3, anion exchanger 1/3; ARMS, alveolar rhabdomyosarcoma; CT, chemotherapy; ES, Ewing's sarcoma; F, female; f, focal; FLI1, Friend leukemia integration-1; FNCLCC, French Federation Nationale des Centres de Lutte Contre le Cancer; L, left; M, male; MPNST, malignant peripheral nerve sheath tumor; NSE, neuron-specific enolase; p TNM, tumor node metastasis (pathological stage); PNET, peripheral neuroectodermal tumor; R, right; $\mathrm{RT}$, radiotherapy; S, surgery; $\mathrm{w}$, weak.

\section{Adults ( $>19$ Years; $n=28$ )}

The age range was from 22 to 75 years (mean age 41.5 years). Osteosarcomas (9/28) were the major contributor in this group followed by chondrosarcoma (conventional grade $1>$ grade II > grade III) (7/28), synovial sarcoma (2/28), MPNST (2/28), undifferentiated pleomorphic sarcoma (2/28), alveolar rhabdomyosarcoma (1/28), embryonal rhabdomyosarcoma (1/28), low-grade myxofibrosarcoma (1/28) ( - Fig. 3A), angiosarcoma (1/28) ( - Fig. 3B), leiomyosarcoma (1/28), and sclerosing epithelioid fibrosarcoma (1/28). Slight male predominance was noted (male:female $=1.3: 1)$ overall. In the case of osteosarcomas, females were affected more and chondrosarcomas affected males predominantly. Chondrosarcomas had the radiological appearance of expansile altered signal intensity lesions whereas osteosarcomas presented with lytic and sclerotic bony lesions with a cortical breach, periosteal reaction, new bone formation, and associated soft tissue component. Among osteosarcomas, the most common histologic type was osteoblastic (5/9), followed by chondroblastic (3/9) and fibroblastic type (1/9). Data on IHC findings, tumor grading, staging, treatment, and recurrence have been produced in - Table 3.

Of the 28 patients, 27 underwent resection. Elective nodal dissection was not routinely performed considering the low rate of regional node metastases in sarcomas except in the patient of angiosarcoma who had tumor metastasis in neck nodes. One patient who did not have surgical excision included the case of ERMS; this patient received RT and systemic chemotherapy. Thirteen of 24 patients undergoing surgical resection also received $\mathrm{RT}$ in an adjuvant (postoperative) manner, with a total dose ranging from 5,000 to 6,600 cGy. Chemotherapy (VDC) was administered to 9 patients, after completing postoperative radiation, on an individualized basis. Two of the patients, one having grade II MPNST and another having grade III UPS, presented with stage pT4a disease as evidenced by their orbital invasion. Of these two patients, lung metastasis was also present in the case of grade III UPS at presentation.

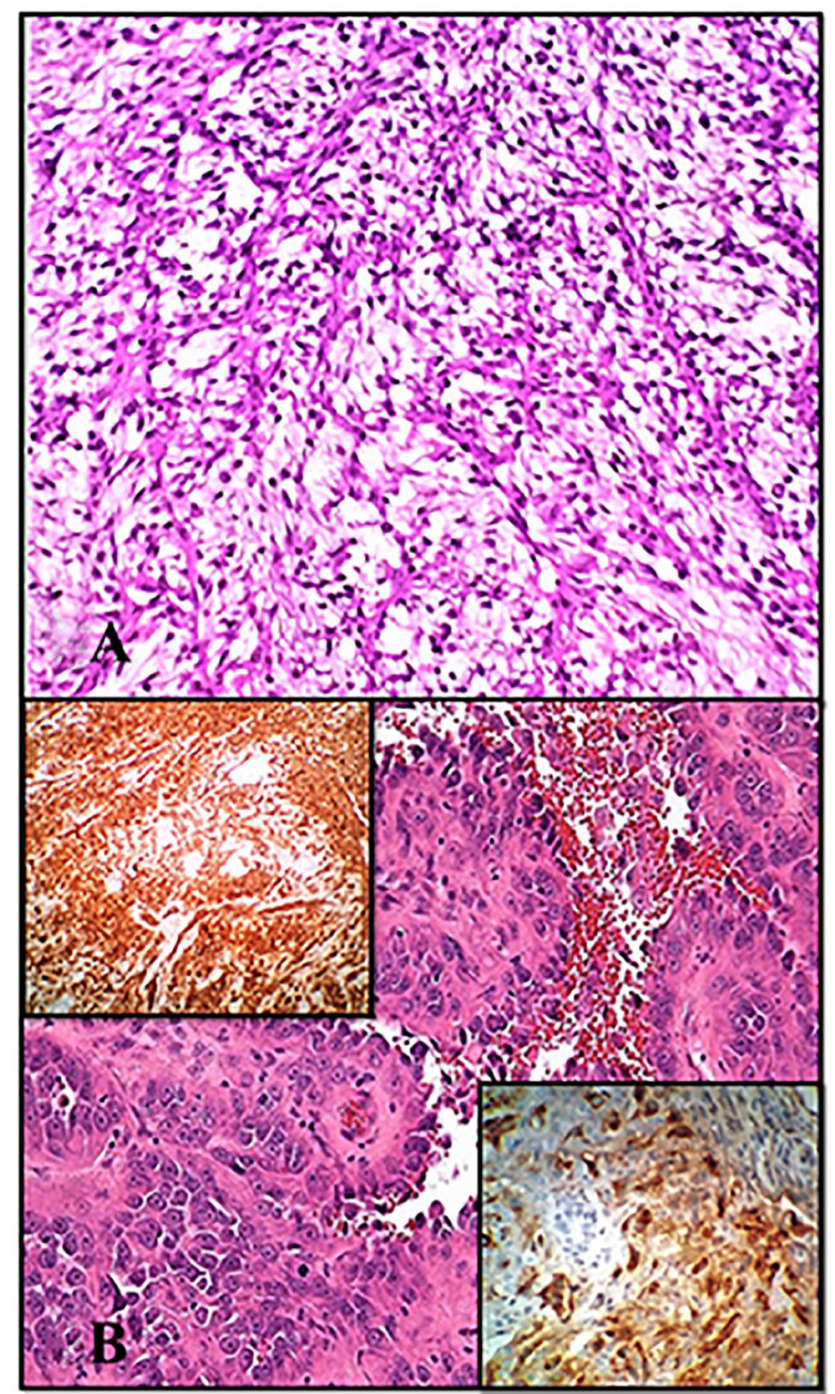

Fig. 3 (A) Low-grade myxofibrosarcoma: tumor cells with oval-tospindle hyperchromatic nuclei in a myxoid stroma (H\&E, $\times 40$ ). (B) Angiosarcoma: tumor cells having round-to-oval hyperchromatic nuclei and prominent nucleoli and a moderate amount of cytoplasm in a hyalinized stroma $(H \& E \times 40)$ (inset: tumor cells express strong cytoplasmic CD31 [upper left corner] and factor VIII-related antigen [lower right corner] [IHC $\times 40])$. 
Table 3 Clinicopathological parameters of sarcomas in adult patients

\begin{tabular}{|c|c|c|c|c|c|c|c|}
\hline \multirow{2}{*}{$\begin{array}{l}\text { HP diagnosis } \\
\text { of sarcoma } \\
(N=28)\end{array}$} & \multirow[t]{2}{*}{ Positive IHC markers } & \multirow[t]{2}{*}{ Grade/risk group } & \multirow[t]{2}{*}{ Stage } & \multirow[t]{2}{*}{ Treatment } & \multicolumn{3}{|c|}{ Recurrence } \\
\hline & & & & & $\mathrm{Y} / \mathrm{N}$ & No. & $\begin{array}{l}\text { Within } \\
\text { (month) }\end{array}$ \\
\hline \multirow[t]{3}{*}{$\operatorname{OS}(n=9)$} & \multirow{3}{*}{$\begin{array}{l}\text { Vimentin, SATB2, } \\
\text { SMA (fibroblastic variant) }\end{array}$} & \multirow[t]{2}{*}{ High grade $(n=8)$} & $\| \mathrm{A}(n=6)$ & $S+C T+R T$ & Y & 3 & 6 \\
\hline & & & IVA $(n=2)$ & $\mathrm{S}+\mathrm{CT}+\mathrm{RT}$ & Y & 1 & 3 \\
\hline & & Low grade $(n=1)$ & IA & $\mathrm{S}+\mathrm{CT}$ & $\mathrm{N}$ & - & - \\
\hline \multirow[t]{3}{*}{$\operatorname{CS}(n=7)$} & \multirow{3}{*}{$\begin{array}{l}\text { Vimentin } \\
\text { S100 }\end{array}$} & Grade I $(n=4)$ & $1 \mathrm{~A}$ & $S+R T$ & $\mathrm{~N}$ & - & - \\
\hline & & Grade II $(n=2)$ & $\| \mathrm{A}$ & $S+R T$ & Y & 1 & 6 \\
\hline & & Grade III $(n=1)$ & $\| A$ & $S+R T$ & Y & 2 & 6 \\
\hline ARMS $(n=1)$ & Vimentin, desmin, MyoD1 & Low risk $(n=1)$ & 1 & $\mathrm{CT}+\mathrm{S}$ & $\mathrm{N}$ & - & - \\
\hline ERMS $(n=1)$ & Vimentin, desmin, MyoD1 & $\begin{array}{l}\text { Intermediate risk } \\
(n=1)\end{array}$ & II & $C T+R T$ & $\mathrm{Y}$ & 1 & 6 \\
\hline LGMFS $(n=1)$ & Vimentin & Grade I $(n=1)$ & pT2N0M0 & $S+R T$ & $\mathrm{~N}$ & - & - \\
\hline LMS $(n=1)$ & Vimentin, SMA, desmin & Grade II $(n=1)$ & pT3N0M0 & $S+R T$ & $\mathrm{~N}$ & - & - \\
\hline \multirow[t]{2}{*}{ MPNST $(n=2)$} & \multirow[t]{2}{*}{ Vimentin, S100(f), SOX10 } & \multirow[t]{2}{*}{ Grade II $(n=2)$} & pT4aN0M0 $(n=1)$ & $\mathrm{S}+\mathrm{RT}+\mathrm{CT}$ & $\mathrm{Y}$ & 1 & 3 \\
\hline & & & pT3 N0 M0 $(n=1)$ & $\mathrm{S}+\mathrm{RT}$ & $\mathrm{N}$ & - & - \\
\hline $\mathrm{SS}(n=2)$ & Vimentin, TLE1, CD99, EMA & Grade III ( $n=2)$ & pT2 N0 M0 & $\mathrm{S}+\mathrm{RT}+\mathrm{CT}$ & $\mathrm{N}$ & - & - \\
\hline \multirow[t]{2}{*}{ UPS $(n=2)$} & \multirow[t]{2}{*}{ Vimentin } & \multirow[t]{2}{*}{ Grade III ( $n=2)$} & pT4aN0M1 $(n=1)$ & $S+C T$ & Y & 1 & 3 \\
\hline & & & P T3 N0M0 $(n=1)$ & $\mathrm{S}+\mathrm{RT}+\mathrm{CT}$ & Y & 1 & 6 \\
\hline $\operatorname{SEFS}(n=1)$ & $\begin{array}{l}\text { Vimentin, S100 (f/w), AE1/ } \\
\text { AE3 (f/w) }\end{array}$ & Grade II $(n=1)$ & $\mathrm{p}$ T2 N0M0 & $S+R T$ & $\mathrm{~N}$ & - & - \\
\hline Angios $(n=1)$ & $\begin{array}{l}\text { Vimentin, CD31, FLI1, FVIII- } \\
\text { related antigen }\end{array}$ & Grade III ( $n=1)$ & p T3N1M0 & $\mathrm{S}+\mathrm{RT}+\mathrm{CT}$ & $\mathrm{Y}$ & 1 & 3 \\
\hline
\end{tabular}

Abbreviations: AngioS, angiosarcoma; ARMS, alveolar rhabdomyosarcoma; CD, cluster of differentiation; CS, chondrosarcoma; CT, chemotherapy; EMA, epithelial membrane antigen; ERMS, embryonal rhabdomyosarcoma; FLI1, Friend leukemia integration-1; HP, histopathological; IHC, immunohistochemistry; LGMFS, low-grade myxofibrosarcoma; LMS, leiomyosarcoma; MPNST, malignant peripheral nerve sheath tumor; N, no; OS, osteosarcoma; p TNM, tumor node metastasis (pathological stage); RT, radiotherapy; S, surgery; SEFS, sclerosing epithelioid fibrosarcoma; SMA, smooth muscle actin; SOX10, SRY-related HMG-box 10; SS, synovial sarcoma; TLE1, transducin-like enhancer of split 1; UPS, undifferentiated pleomorphic sarcoma; Y, yes.

Tumor recurrence was documented in 12 patients. Of these 12,11 patients had local recurrence, and one patient with high-grade OS developed lung metastasis. Meantime interval for recurrence was 4.6 months (range 3-6 months).

\section{Discussion}

The exact etiology of head and neck sarcoma is unknown. However, the etiology of sarcomas can be idiopathic, genetically predisposing, radiation exposure, viral, or chemical carcinogenic-induced. ${ }^{7}$ The most common symptom of head neck soft tissue sarcoma is a painless mass (in $80 \%$ of cases). Pain may be present occasionally and it is the most common presenting symptom in bone sarcomas. ${ }^{8}$ Imaging plays an important role in defining the extent of the tumor and for planning the appropriate surgical procedures. Due to the complexity of the anatomy of the head and neck region, combined magnetic resonance imaging (MRI) and computed tomography (CT) scan are recommended. ${ }^{7}$

Due to the rarity of primary head and neck sarcomas, most of the published series have a small number of sample sizes. ${ }^{9,10}$ Primary sarcomas represented $0.06 \%$ of total cancer cases and $2.4 \%$ of total sarcoma cases in our study. Embryonal rhabdomyosarcoma and OS were the most common histological variants in pediatric ( $<12$ years) and adolescent
(12-18 years) patients, respectively. A study conducted by Atarbashi-Moghadam et al ${ }^{11}$ also found rhabdomyosarcomas and osteosarcomas as typical variants in this age group. Additionally, we found ES/PNET to be a common variant in adolescents. In pediatric patients, our finding of the nasopharynx and nasal sinuses as common sites is in line with other studies. ${ }^{12,13}$

We had one case of small-cell osteosarcoma (OS) in a 13-year-old girl affecting the $\mathrm{C} 7$ vertebra. This entity needs special mention because of difficulty in diagnosis when there is very focal or less amount of osteoid material in the tumor. Although classified as OS based on its production of osteoid, the histomorphology differs from those of conventional OS in that the cells are smaller with less cytoplasm and uniform. The differential diagnosis of small-cell OS includes other small round blue cell tumors, including non-Hodgkin lymphomas, small-cell carcinoma, neuroblastoma, mesenchymal chondrosarcoma, and Ewing's sarcoma/primitive neuroectodermal tumor (ES/PNET). ${ }^{14-16}$ In this scenario, addition of the immunomarker SATB2 to the panel solves the problem as the none of the other small round cell tumors other than the small-cell OS expresses diffuse nuclear immunoreactivity. The most important reason to identify small-cell OS is to guide appropriate therapy. Although the treatment of small-cell OS has not been optimized (owing to its rarity), 
small-cell OS is most often treated like conventional osteosarcoma, with neoadjuvant chemotherapy followed by surgical resection. ${ }^{14,15}$ Mesenchymal chondrosarcoma is not treated with chemotherapy, and the chemotherapeutic protocols for small-cell carcinoma, non-Hodgkin lymphomas, ES/PNET, and OS are different. Specifically, OS is most often treated with a regimen of cisplatin, doxorubicin, and high-dose methotrexate, ${ }^{17}$ whereas ES/PNET is most often treated with doxorubicin, cyclophosphamide, vincristine, and dactinomycin. ${ }^{18}$ However, in cases in which a tumor cannot be definitively placed into the small-cell OS or ES/PNET category, authorities recommend treating the tumor as an ES/PNET. ${ }^{14,15}$

For the adult patients, our results were also corroborative with other studies. The mandible was the most frequently involved site of occurrence, which is similar to the results of previous reports. ${ }^{19-22}$ We found slight male gender predilection (male:female ratio 1.3) in adult population, corroborative with other studies. ${ }^{11}$ In our study, osteosarcomas had a higher female predilection, similar to the findings of previously published studies conducted by Atarbashi-Moghadam et $\mathrm{al}^{11}$ and Guevara-Canales et $\mathrm{a}^{23}$ whereas chondrosarcomas affected predominantly male adult patients.

Surgery remains the mainstay of treatment for head and neck sarcomas. Exceptions to this principle include most rhabdomyosarcomas and Ewing's sarcomas. RT is indicated after resection of sarcomas with high-grade, large tumors, and when resection margins are close or microscopically involved. Systemic chemotherapy is recommended for tumors with a significant risk of distant metastases.

Right cervical lymphadenopathy was detected in a 75-year-old man having angiosarcoma of the right parotid gland. He had a local tumor recurrence within 3 months of treatment completion. Several authors have suggested lymphadenopathy at diagnosis to be a poor prognostic factor. ${ }^{4,24,25}$ Head and neck soft tissue sarcomas show low rates of lymphadenopathy at presentation, varying from 7 to $10 \%$ in different studies. ${ }^{3,25}$ Therefore, most authors do not recommend neck dissection routinely except in case of clinically or radiologically indicated. ${ }^{2}$

In our study, out of 40 cases, 19 cases (47.5\%) had a disease relapse within a period of 6 months from the completion of therapy. Two out of 28 adult patients (7.14\%) developed lung metastasis at the time of the initial presentation. In literature, in up to $21 \%$ cases, metastasis has been documented to lung, bone, or brain. ${ }^{26,27}$ High local failure rates in the head and neck have been associated with poorer treatment outcomes despite the finding that sarcomas arising in the head and neck have a lower probability of distant spread. At relapse, repeat surgery and/or radiation should be considered to maximize the disease control. ${ }^{25}$ Also, clinical trials to investigate novel systemic therapies for these patients remain a priority.

\section{Conclusion}

Head and neck sarcomas often pose difficulties in management because of their high local failure rates due to the anatomical complexity of the vital structures in the head and neck. Timely diagnosis, accurate staging, and multidisciplinary treatment plan are of utmost importance to yield the optimal patient outcome.

\section{Conflict of Interest}

None declared.

\section{Acknowledgments}

The authors acknowledge all the technical staff in histopathology and immunohistochemistry department of our institute, especially Ms. Bhoomika M. Rathod for her contribution in searching and acquisition of data.

\section{References}

1 Potter BO, Sturgis EM. Sarcomas of the head and neck. Surg Oncol Clin N Am 2003;12(2):379-417

2 Eeles RA, Fisher C, A'Hern RP, et al. Head and neck sarcomas: prognostic factors and implications for treatment. Br J Cancer 1993;68(1):201-207

3 Van Damme JP, Schmitz S, Machiels JP, et al. Prognostic factors and assessment of staging systems for head and neck soft tissue sarcomas in adults. Eur J Surg Oncol 2010;36(7):684-690

4 Mücke T, Mitchell DA, Tannapfel A, et al. Outcome in adult patients with head and neck sarcomas-a 10-year analysis. J Surg Oncol 2010;102(2):170-174

5 de Bree R, van der Waal I, de Bree E, Leemans CR. Management of adult soft tissue sarcomas of the head and neck. Oral Oncol 2010;46(11):786-790

6 MendenhallWM, MendenhallCM, Werning.JW, RiggsCE, MendenhallNP. Adult head and neck soft tissues sarcomas. Head Neck 2005;10:916-919

7 Patel SG, Shaha AR, Shah JP. Soft tissue sarcomas of the head and neck: an update. Am J Otolaryngol 2001;22(1):2-18

8 Wanebo HJ, Head and neck sarcoma. In: Johnson JT, Didolker MS, eds. Head and Neck Cancer. Amsterdam, Netherlands: Elsevier Science; 1993 3;39-47

9 Breakey RW, Crowley TP, Anderson IB, Milner RH, Ragbir $M$. The surgical management of head and neck sarcoma: the Newcastle experience. J Plast Reconstr Aesthet Surg 2017;70(1):78-84

10 Lajer CB, Daugaard S, Hansen HS, Kirkegaard J, Holmgaard S, Christensen ME. Soft tissue sarcomas of the head and neck: a single-centre experience. Clin Otolaryngol 2005;30(2): 176-182

11 Atarbashi-Moghadam S, Emami Razavi AN, Salehi Zalani S. Prevalence of head and neck sarcoma in a major cancer center in Iran-a 10-year study. Iran J Otorhinolaryngol 2019; 31(103):97-102

12 Barosa J, Ribeiro J, Afonso L, Fernandes J, Monteiro E. Head and neck sarcoma: analysis of 29 cases. Eur Ann Otorhinolaryngol Head Neck Dis 2014;131(2):83-86

13 Stavrakas M, Nixon I, Andi K, et al. Head and neck sarcomas: clinical and histopathological presentation, treatment modalities, and outcomes. J Laryngol Otol 2016;130(9):850-859

14 Unni KK, Inwards CY, Bridge JA, Kindblom LG, Wold LE, Small cell osteosarcoma. In: Tumors of the Bones and Joints. 4th ed. Washington, DC: American Registry of Pathology Press; 2005:299

15 Nakajima H, Sim FH, Bond JR, Unni KK. Small cell osteosarcoma of bone. Review of 72 cases. Cancer 1997;79(11):2095-2106

16 Hameed M. Small round cell tumors of bone. Arch Pathol Lab Med 2007;131(2):192-204

17 Sakamoto A, Iwamoto Y. Current status and perspectives regarding the treatment of osteo-sarcoma: chemotherapy. Rev Recent Clin Trials 2008;3(3):228-231

18 Miser JS, Krailo MD, Tarbell NJ, et al. Treatment of metastatic Ewing's sarcoma or primitive neuroectodermal tumor of bone: 
evaluation of combination ifosfamide and etoposide-a children's cancer group and pediatric oncology group study. J Clin Oncol 2004;22(14):2873-2876

19 Alishahi B, Kargahi N, Homayouni S. Epidemiological evaluation of head and neck sarcomas in Iran (the study of 105 cases over 13 years) Iran J Cancer Prev 2015;8(4):e3432

20 Brady JS, Chung SY, Marchiano E, Eloy JA, Baredes S, Park RCW. Pediatric head and neck bone sarcomas: an analysis of 204 cases. Int J Pediatr Otorhinolaryngol 2017;100:71-76

21 Stewart BD, Reith JD, Knapik JA, Chi AC. Bone- and cartilage-forming tumors and Ewing's sarcoma: an update with a gnathic emphasis. Head Neck Pathol 2014;8(4):454-462

22 Jasnau S, Meyer U, Potratz J, et al. Cooperative Osteosarcoma Study Group COSS. Craniofacial osteosarcoma experience of the cooperative German-Austrian-Swiss osteosarcoma study group. Oral Oncol 2008;44(3):286-294

23 Guevara-Canales JO, Sacsaquispe-Contreras SJ, Morales-Vadillo $\mathrm{R}$, Sánchez-Lihón J. Epidemiology of the sarcomas of the jaws in a Peruvian population. Med Oral Patol Oral Cir Bucal 2012;17(2):e201-e205

24 González-González R, Bologna-Molina R, Molina-Frechero N, Domínguez-Malagon HR. Prognostic factors and treatment strategies for adult head and neck soft tissue sarcoma. Int J Oral Maxillofac Surg 2012;41(5):569-575

25 de Bree R, van der Valk P, Kuik DJ, et al. Prognostic factors in adult soft tissue sarcomas of the head and neck: a single-centre experience. Oral Oncol 2006;42(7):703-709

26 Guadagnolo BA, Zagars GK, Raymond AK, Benjamin RS, Sturgis EM. Osteosarcoma of the jaw/craniofacial region: outcomes after multimodality treatment. Cancer 2009;115(14): 3262-3270

27 Chennupati SK, Norris R, Dunham B, Kazahaya K. Osteosarcoma of the skull base: case report and review of literature. Int J Pediatr Otorhinolaryngol 2008;72(1):115-119 